\title{
PENERAPAN ALGORITMA INTERPOLATIVE CODING UNTUK KOMPRESI FILE AUDIO
}

\author{
Riyo Oktavianty Finola \\ Program Study Teknik Informatika STMIK Budi Darma Medan, Indonesia \\ Email: riyooktaviantyfinola96@gmail.com
}

\begin{abstract}
Abstrak
Besarnya ukuran file audio dapat mempengaruhi waktu pengiriman data menjadi lama dan dapat menyebabkan pemborosan ruang penyimpanan. Oleh karena itu dilakukan kompresi untuk memampatkan isi file audio menjadi lebih kecil, salah satu tenik kompresi adalah teknik lossless yaitu metode kompresi dimana pada file audio hasil kompresi dapat dikembalikan ke file sebelum di kompres tanpa menghilangkan informasi pada data sebelumnya. Penelitian ini menggunakan algoritma Interpolative coding pada file audio berformat mp3. Algoritma Interpolative coding merupakan cara yang inovatif untuk menetapkan kode dinamis ke simbol data. Metode ini berbeda dari metode kompresi lainnya, karena kode yang diberikannya untuk simbol individual tidak statis. Perancangan sistem ini terdiri dari 2 proses utama yaitu proses kompresi dan proses dekompresi dan proses menghitung kinerja Compression Ratio (CR) dan Redudancy. Hasil kompresi menghasilkan file baru yang berekstensi *.ipc yang berisi string bit hasil kompresi yang selanjutnya akan bisa di dekompresi. Aplikasi yang dirancang hanya satu form, dimana didalam form tersebut ada proses untuk kompresi dan dekompresi, disaat proses kompresi file yang di input berekstensi *.mp3 dan menghasilkan output berekstensi *ipc, dan ukuran file audio yang di kompresi lebih kecil dari pada ukuran file sebelumnya.
\end{abstract}

Kata Kunci : Kompresi, File Audio, Algoritma Interpolative coding

\begin{abstract}
The size of the audio file can affect the time of sending data to be long and can cause waste of storage space. Therefore, compression is performed to compress the contents of the audio file into smaller ones. One of the compression techniques is lossless technique, which is a compression method where the compressed audio file can be returned to the file before it is compressed without losing information on the previous data. This study uses the Interpolative coding algorithm on mp3 audio files. Interpolative coding algorithm is an innovative way to assign dynamic code to data symbols. This method is different from other compression methods, because the code it provides for individual symbols is not static. The design of this system consists of 2 main processes namely the compression process and the decompression process and the process of calculating the performance of Compression Ratio (CR) and Redundancy. The resulting compression results in a new file with the *.ipc extension containing the compressed bit string which can then be decompressed. Application designed only one form, where in the form there is a process for compression and decompression, while the process of compressing the input file has the extension *.MP3 and produces output with the extension *IPC, and the size of the compressed audio file is smaller than the previous file size .
\end{abstract}

Keywords: Compression, Audio File, Interpolative coding algorithm

\section{PENDAHULUAN}

Sebagian masyarakat menjadikan musik sebagai pembangkit semangat atau bahkan dijadikan sebagai media untuk menemukan ketenangan. Pentingnya musik dalam kehidupan masyarakat dapat dilihat dari banyaknya file musik yang tersimpan dalam perangkat teknologi yang dimiliki. Saat ini masyarakat lebih mudah mendapatkan file dari musik yang disenangi dengan mengunduh file musik tersebut dari internet. File musik yang diunduh umumnya merupakan file audio dengan format $\mathrm{Mp3}$, namun kualitas musik dari file audio yang diunduh tersebut bergantung dengan ukuran file yang diunduh. Semakin baik kualitas yang diinginkan maka ukuran file audio akan semakin besar. Oleh karena itu, untuk dapat menyimpan file audio dengan kualitas yang baik maka harus menyiapkan storage yang lebih besar. Untuk menanggulangi permasalahan tersebut diperlukan suatu teknik yang mampu mengurangi ukuran file audio namun tidak merubah kualitas dari file audio tersebut.

Kompresi merupakan proses yang dilakukan untuk mengubah sebuah ukuran file yang besar menjadi lebih kecil sehingga dapat disimpan secara efisien. Kompresi file audio dilakukan dengan cara memadatkan isi file sehingga ukurannya menjadi lebih kecil dan tetap menjaga kualitas dari file audio tersebut. Banyak algoritma yang dapat digunakan pada proses kompresi, salah satunya adalah algoritma Interpolative Coding.

Algoritma Interpolative Coding merupakan cara yang inovatif untuk menetapkan kode dinamis ke simbol data. Metode ini berbeda dari metode kompresi lainnya, karena kode yang diberikannya untuk simbol individual tidak statis dan bergantung pada keseluruhan pesan dari pada pada simbol dan frekuensinya. Seluruh pesan yang di-encode harus tersedia untuk pembuat encode. Encode dilakukan dengan memindai pesan dalam urutan khusus, tidak secara linier dari awal hingga akhir, dan menugaskan codeword ke simbol saat bertemu[1]. Algoritma Interpolative Coding dapat menghitung batas bawah dan atas setiap dokumen yang mengidentifikasi kode biner tanpa menggunakan proses perulangan, sehingga waktu kompresi dapat sangat berkurang.

Algoritma Interpolative Coding merupakan jenis teknik kompresi lossless. Dengan menggunakan teknik kompresi lossless dimana hasil data yang di kompres dapat dikembalikan lagi ke data aslinya dan tidak menghilangkan data sebelumnya. Dengan menerapkan algoritma Interpolative Coding penulis ingin mengetahui kinerja kompresi 
apabila dilakukan dengan mengkompresi file Mp3, sehingga file Mp3 yang berukuran besar akan dikompresi menjadi ukuran yang lebih kecil. Sehingga proses transmisi yang dilakukan lebih cepat serta memperkecil ruang penyimpanan.

\section{TEORITIS}

\subsection{KOMPRESI}

Kompresi adalah teknik memperkecil atau memampatkan file yang berukuran besar menjadi lebih kecil dan mengurangi kebutuhan ruang penyimpanan. Proses kompresi merupakan proses yang mendekati pada minimisasi jumlah bit untuk representasi digital seperti gambar, audio, dan video, yang menghasilkan ukuran data yang lebih kecil namun tetap menjaga kuantitas informasi dalam data tersebut[2]. Kompresi audio adalah proses memperkecil atau meminimalisasi jumlah tiap bit yang merepresentasikan suatu audio dengan data yang menjadi lebih kecil.

Teknik kompresi dapat diklarifikasikan menjadi 2 (Dua) berdasakan hasil kompresinya yaitu[2]:

1. Lossless Compression

Lossless compression merupakan teknik kompresi yang tidak menghilangkan data sebelumnya, dimana hasil data yang di kompres dapat dikembalikan lagi ke data aslinya. Ratio kompresi dengan menggunakan metode lossless compression sangat rendah.

2. Lossy Compression

Lossy compression merupakan teknik kompresi yang menghasilkan file data hasil kompresi yang tidak bisa dikembalikan menjadi file data sebelumnya. Ketika data yang dikompresi di decode kembali, maka beberapa bagian data yang hilang dan tidak sama jika data tersebut di kembalikan pada hasil decoding. Dan metode ini menghasilkan ratio kompresi yang lebih tinggi dari pada metode lossless.

Ada beberapa teknik yang dijadikan kriteria untuk menunjukkan kualitas atau kinerja dari suatu metode kompresi, yaitu[1]:

1. Compression Ratio $(\mathrm{RC})$

Compression ratio merupakan presentasi data yang sudah di kompresi yang di dapat dari hasil perbedaan antara ukuran data yang belum di kompresi dengan yang sudah di kompresi.

$C r=\frac{\text { Ukuran Data Setelah Di Kompresi }}{\text { Ukuran Data Sebelum Di Kompresi }} \times 100 \%$

\section{Redudancy}

Redundancy merupakan penyimpanan data yang diartikan menjadi informasi yang bertumpuk, beberapa basis data yang sama, karateristik yang serupa, struktur yang sama dan lainnya.

$$
R d=\frac{\text { file sebelum di kompresi }- \text { file setelah di kompres }}{\text { Ukuran file sebelum di kompresi }} \times 100 \%
$$

\subsection{INTERPOLATIVE CODING}

Algoritma Interpolative Coding merupakan metode yang inovatif untuk menetapkan kode dinamis ke simbol data. Ini berbeda dari metode pengkodean lainnya, karena kode yang diberikannya untuk simbol individual tidak statis dan bergantung pada keseluruhan pesan daripada simbol dan frekuensinya. Seluruh pesan yang di-encode harus tersedia untuk pembuat encode. Pengkodean dilakukan dengan memindai pesan dalam urutan khusus, tidak secara linier dari awal hingga akhir, dan menugaskan codeword ke simbol saat bertemu. Akibatnya, codeword yang ditetapkan untuk simbol bergantung pada urutan simbol dalam pesan[1].

Pohon biner adalah struktur data yang digunakan beberapa algoritma untuk kompresi. Begitu pula dengan algoritma Interpolative Coding, Pohon biner pada Interpolative Coding digunakan untuk menentukan urutan penyelesaian dari sebuah string. Pohon biner yang telah dibangun, seringkali harus dilalui. Untuk melintasi pohon berarti mengulangnya dengan cara sistematis dengan mengunjungi setiap simpul satu kali. Melintasi pohon biner sering dilakukan di preorder, inorder, atau pastorder. Ketiga metode ini bersifat rekursif dan dijelaskan dalam setiap teks pada struktur data. Prinsip inorder traversal adalah untuk :

1. Melintasi subtree kiri secara rekursif di inorder

2. Mengunjungi root

3. Melintasi subtree kanan secara rekursif di inorder

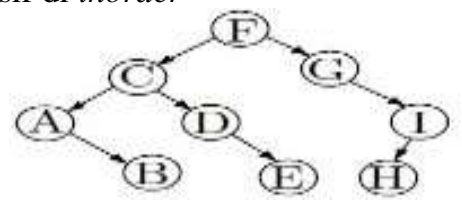

Gambar 1.Pohon biner 
Sumber : David Salomon, Giovanni Motta, 2010[1]

Dari penjelasan di atas maka dapat dirumuskan algoritma Interpolative Coding untuk mengompresi file audio dengan langkah-langkah sebagai berikut[1]:

1. Baca semua karakter yang ada dalam teks untuk menghitung frekuensi kemunculan dari masing-masing karakter.

2. Masukkan nilai masing-masing frekuensi kemunculan karakter lalu jumlahkan kumulatif secara berurutan.

a. $\mathrm{M}=$ nilai dari masing-masing frekuensi

b. $\mathrm{L}=$ elemen atau nilai kumulatif dari $\mathrm{M}$

3. Interpolative Coding memproses data tersebut kemudian dibuatkan pohon biner untuk menentukan urutan penyelesaiannya. Dengan mengambil nilai tengah sebagai root dari pohon biner.

4. Interpolative Coding mengkompresi string dengan cara mengencode panjang dari L (elemen) yang berada di tengah.

\section{$\mathrm{L}=\mathrm{X}, \mathrm{X}, \mathrm{X}, \mathrm{X}, \mathrm{X}, \mathrm{X}, \mathrm{X}, \mathrm{X}, \mathrm{X}$}

5. Ketika mengencode elemen yang berada ditengah, maka kita mengeksploitasi elemen awal dengan panjang elemen yang mendahului dan elemen yang mengikuti yang sudah diketahui.

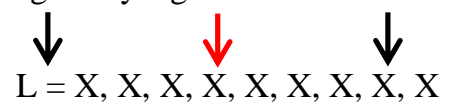

6. Perhatikan L [tengah] mendahului 4 elemen, dan diikuti 4 elemen, maka:

$\mathrm{L}$ [tengah] = elemen awal + jumlah elemen yang mendahuluinya

$\mathrm{L}$ [tengah] = elemen akhir - jumlah elemen yang mengikutinya

7. Selanjutnya mencari nilai Range = Nilai Indeks - (hasil nilai encode yang mendahului) hasil dari nilai range nantinya akan di ubah menjadi bilangan biner.

8. Lalu lakukan pembacaan panjang bit dengan mengunakan $=2+($ CEILING MATH(LOG(hasil elemen yang mengikuti - hasil elemen yang mendahului+1) jika hasil bit kurang dengan panjang bit maka nilai bit nya ditambah sesuai dengan panjang bit yang di dapat. Jika panjang bit lebih banyak dari hasil pembacaan panjang bit maka tidak perlu ditambahkan lagi.

9. Kemudian lakukan langkah selanjutnya secara rekursif untuk mengencode semua elemen.

Hasil dari penjumlahan elemen tersebut lalu diubah kebilangan biner yang nantinya akan menjadi codeword.

\section{ANALISIS DAN PEMBAHASAN}

\subsection{Penerapan Interpolative Coding untuk Kompresi File Audio}

Dalam menganalisa file Mp3 yang harus dilakukan adalah mengambil sample file Mp3 dengan melakukan pembacaan file Mp3. Pembacaan file Mp3 dilakukan untuk mendapatkan nilai dari data pada sebuah file Mp3 yang berupa bilangan hexadesimal. Dalam proses hitungan manual nilai sample file Mp3 diambil menggunakan sofware Binary Viewer, kemudian data nilai hexadesimal Mp3 di kompresi menggunakan algoritma Interpolative coding. Berikut informasi objek file MP3 yang akan diambil samplenya sebelum dilakukan kompresi.

Tabel 1. Informasi File Mp3 Sample

\begin{tabular}{lc}
\hline & Keterangan \\
\hline Jenis File & MP3 \\
Judul & Treat you Better \\
Ukuran & $7,82 \mathrm{MB}$ \\
Durasi & $4.16 \mathrm{Menit}$ \\
\hline
\end{tabular}

Pada tahap ini akan dilakukan pembentukan bilangan heksadesimal yang terdapat pada file Audio. Untuk mendapatkan nilai biner dari file audio yang akan dikompresi ialah dengan menggunakan aplikasi Binary Viewer. 


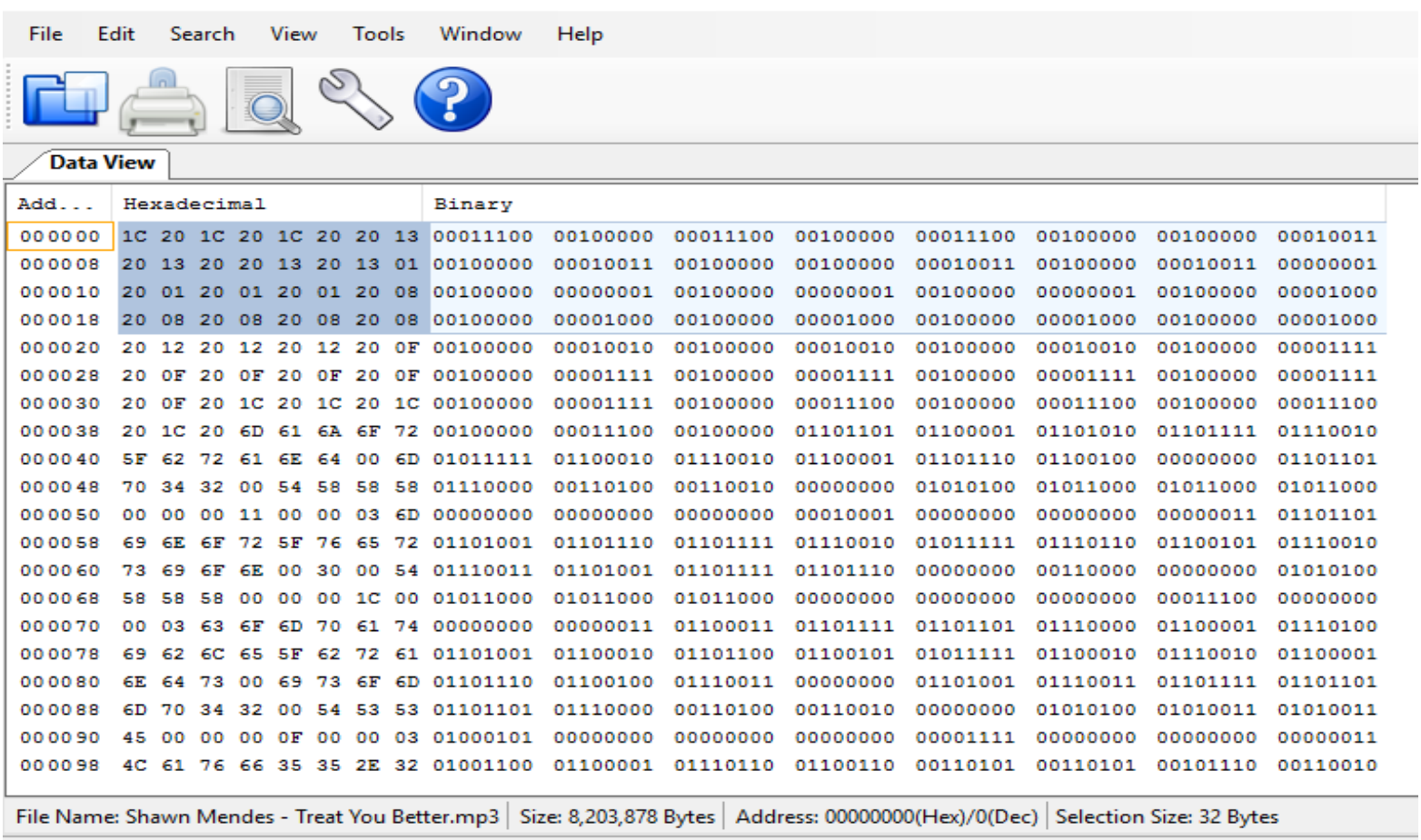

Gambar 2. nilai heksadesimal dan binary file $\mathrm{mp} 3$

Berdasarkan pada gambar di atas didapat nilai heksadesimal file mp3. Untuk keperluan hitungan manual hanya diambil sampel nilai sebanyak 32 bilangan heksadesimal file mp3. Adapun bilangan heksadesimal file mp3 sampel tersebut adalah 1C 20 1C 20 1C 20201320132020132013012001200120012008200820082008 2008.

Tabel 2. Nilai Biner yang akan dikompresi

\begin{tabular}{ccccc}
\hline Nilai Heksadesimal & Nilai Biner & Bit & Freq & Bit x Freq \\
\hline $1 C$ & 00011100 & 8 & 3 & 24 \\
20 & 00100000 & 8 & 16 & 128 \\
13 & 00010011 & 8 & 4 & 32 \\
01 & 00000001 & 8 & 4 & 32 \\
08 & 00001000 & 8 & 5 & 40 \\
\hline
\end{tabular}

Setelah menghitung data sebelum dikompresi, dari tabel di atas dilakukan kompresi menggunakan Algoritma Interpolative Coding, dengan mengkodekan bilangan heksadesimal yang muncul berdasarkan urutan kemunculannya.

1. Masukkan nilai frekuensi 5 kemunculan bilangan heksadesimal $\mathrm{M}=(3,16,4,4,5)=32$

2. Kemudian encode nilai dimulai dengan menghitung 5 frekuensi kemunculan bilangan heksadesimal secara kumulatif $\mathrm{L}=(3,19,23,27,32)$

3. Interpolative Coding memproses data tersebut kemudian dibuatkan pohon biner untuk menentukan urutan penyelesaiannya. Membuat pohon biner menggunakan nilai tengah sebagai root dari pohon biner.<smiles>CCOC</smiles>

4. Kemudian dilanjutkan dengan meng-encode elemen 3 yang ada ditengah. Ketika meng-encode L [3] maka kita mengeksploitasi L [1] dengan panjang elemen yang mendahuluinya yang sudah diketahui oleh decoder.

Tabel 3. Nilai Indeks

\begin{tabular}{cccccc}
\hline Indeks L & 1 & 2 & 3 & 4 & 5 \\
\hline Nilai & 3 & 19 & 23 & 27 & 32 \\
\hline
\end{tabular}

5. L [3] mendahului 2 elemen

L [3] mengikuti 2 elemen

Lalu encode L [3] = elemen awal + jumlah elemen yang mendahuluinya

Lalu encode L [3] = elemen akhir - jumlah elemen yang mengikutinya

$\mathrm{L}[3]=3+2=5$

$\mathrm{L}[3]=32-2=30$ 
Nilai Range $23-5=18$ maka nilai Binernya adalah 10010

$=2+($ CEILING.MATH $(\operatorname{LOG}(30-5+1)))=4$ bit

Tabel 4. Nilai Indeks

\begin{tabular}{cccccc}
\hline Indeks L & 1 & 2 & 3 & 4 & 5 \\
\hline Nilai & 3 & 19 & 23 & 27 & 32 \\
\hline
\end{tabular}

6. L [2] mendahului 1 elemen

L [2] mengikuti 1 elemen

Lalu encode L [2] = elemen yang mendahului + jumlah elemen yang mendahuluinya

Lalu encode L [2] = elemen akhir - jumlah elemen yang mengikutinya

$\mathrm{L}[2]=3+1=4$

$\mathrm{L}[2]=23-1=22$

Nilai Range $19-4$ = 15 maka nilai Binernya adalah 1111

$=2+($ CEILING.MATH $($ LOG $(22-4+1)=4$ bit

Tabel 5. Nilai Indeks

\begin{tabular}{cccccc}
\hline Indeks L & 1 & 2 & 3 & 4 & 5 \\
\hline Nilai & 3 & 19 & 23 & 27 & 32 \\
\hline
\end{tabular}

7. L [1] mendahului 0 elemen

L [1] mengikuti 1 elemen

Lalu encode L [1] = elemen yang mendahului + jumlah elemen yang mendahuluinya

Lalu encode $\mathrm{L}[1]$ = elemen akhir - jumlah elemen yang mengikutinya

$\mathrm{L}[1]=3+0=3$

$\mathrm{L}[1]=19-1=18$

Nilai Range $3-3=0$ maka nilai Binernya adalah 0

$=2+($ CEILING.MATH $($ LOG $(18-3+1)=4$ bit

\begin{tabular}{cccccc}
\multicolumn{7}{c}{ Tabel 6 Nilai Indeks } \\
\hline Indeks L & 1 & 2 & 3 & 4 & 5 \\
\hline Nilai & 3 & 19 & 23 & 27 & 32 \\
\hline
\end{tabular}

8. L [4] mendahului 1 elemen

L [4] mengikuti 1 elemen

Lalu encode L [4] = elemen yang mendahului + jumlah elemen yang mendahuluinya

Lalu encode L [4] = elemen akhir - jumlah elemen yang mengikutinya

$\mathrm{L}[4]=23+1=24$

$\mathrm{L}[4]=32-1=31$

Nilai Range $27-24=3$ maka nilai Binernya adalah 11

$=2+($ CEILING.MATH $($ LOG $(31-24+1)=3$ bit

Tabel 7. Nilai Indeks

\begin{tabular}{cccccc}
\hline Indeks L & 1 & 2 & 3 & 4 & 5 \\
\hline Nilai & 3 & 19 & 23 & 27 & 32 \\
\hline
\end{tabular}

9. L [5] mendahului 1 elemen

L [5] mengikuti 0 elemen

Lalu encode L [5] = elemen yang mendahului + jumlah elemen yang mendahuluinya

Lalu encode L [5] = elemen akhir - jumlah elemen yang mengikutinya

$\mathrm{L}[5]=27+1=28$

$\mathrm{L}[5]=32-0=32$

Nilai Range $32-28=4$ maka nilai Binernya adalah 100

$=2+($ CEILING.MATH $($ LOG $(32-28+1)=3$ bit

Tabel 8. hasil kompresi algoritma Interpolative Coding

\begin{tabular}{lccccc}
\hline Elemen & Nilai Hexa & Interpolative Coding & Bit & Frek & Bit x Frek \\
\hline L3 $=13$ & 12 & 10010 & 5 & 4 & 20 \\
L2=20 & F & 1111 & 4 & 16 & 64 \\
L1=1C & 0 & 0000 & 4 & 3 & 12 \\
L4=08 & 3 & 011 & 3 & 4 & 12 \\
L5=01 & 4 & 100 & 3 & 5 & 15 \\
\hline \multicolumn{7}{r}{} \\
\hline
\end{tabular}


Berdasarkan tabel 3.8 dapat dilihat bahwa bentuk string bit dari nilai heksadesimal "1C, 20, 1C, 20, 1C, 20, $20,13,20,13,20,20,13,20,13,01,20,01,20,01,20,01,20,08,20,08,20,08,20,08,20,08$," setelah dikompresi yaitu:

0000111100001111000011111111100101111100101111111110010111110010100111110011111001111 10011110111111011111101111110111111011

Sebelum di dapatkan hasil akhir kompresi dilakukan penambahan string bit itu sendiri yaitu padding bit dan flag bit. Penambahan bit (padding) dilakukan jika hasil kompresi di bagi 8 memiliki sisa. Sedangkan hasil kompresi tidak memiliki sisa atau nol maka tidak perlu adanya penambahan bit (padding). Sedangkan flag bit adalah nilai biner yang didapat dari nilai hasil padding. Flag bit memiliki jumlah nilai 8 bit biner. Berdasarkan hasil kompresi nilai heksadesimal file audio sampel menggunakan algoritma interpolative coding di dapat nilai string bit sebanyak 123 bit dimana jika bilangan tersebut dibagi 8, maka akan menghasilkan sisa bagi sebanyak tiga digit. Maka diperoleh padding 00000 “0000111100001111000011111111100101111100101111111110010111110010100111110011111001111100111101 1111101111110111111011111101100000” Dengan penambahan padding sebanyak tuju bit, maka diperoleh flag 00000101 Maka diperoleh string bit baru sebagai berikut

“0000111100001111000011111111100101111100101111111110010111110010100111110011111001111100111101 $111110111111011111101111110110000000000101 ”$

Maka, jumlah Total panjang bit keseluruhan setelah ada penambahan padding bit dan flag bit adalah $123+5$ $+8=136$. Selanjutnya lakukan pemisahan bit menjadi beberapa kelompok. Setiap kelompok terdiri dari 8 bit sebagai berikut.

“0000111100001111000011111111100101111100101111111110010111110010100111110011111001111100 111101111110111111011111101111110110000000000101 ”

Hasil string bit kode interpolative coding dipisah menjadi 8 bagian agar dapat diubah ke dalam nilai heksadesimal yaitu dapat dilihat pada tabel berikut :

Tabel 9. Nilai Biner dan Heksadesimal hasil kompresi keseluruhan

\begin{tabular}{cc}
\hline Binary & Hexadecimal \\
\hline 00001111 & $\mathrm{~F}$ \\
00001111 & $\mathrm{~F}$ \\
00001111 & $\mathrm{~F}$ \\
11111001 & $\mathrm{~F} 9$ \\
01111100 & $7 \mathrm{C}$ \\
10111111 & $\mathrm{BF}$ \\
11100101 & $\mathrm{E} 5$ \\
11110010 & $\mathrm{~F} 2$ \\
10011111 & $9 \mathrm{~F}$ \\
00111110 & $3 \mathrm{E}$ \\
01111100 & $7 \mathrm{C}$ \\
11110111 & $\mathrm{~F} 7$ \\
11101111 & $\mathrm{EF}$ \\
11011111 & $\mathrm{DF}$ \\
10111111 & $\mathrm{BF}$ \\
01100000 & 60 \\
00000101 & 5
\end{tabular}

File audio yang telah dikompresi dengan algoritma Interpolative Coding, tipe filenya akan diubah menjadi tipe file baru dengan ekstensi yang telah ditentukan sebagai pengenal bahwa file tersebut adalah file yang telah dikompresi dengan aplikasi kompresi yang menerapkan algoritma Interpolative Coding. Ekstensi file yang ditentukan adalah (*.ipc).

\subsection{Parameter Kinerja Kompresi dari Algoritma Interpolative Coding}

Untuk mengetahui tingkat kinerja suatu algoritma kompresi, maka kita harus mengukur hasil kompresi file teks tersebut. Semakin kecil ukuran file yang dikompresi berarti semakin berkualitas tingkat kinerja kompresinya begitu pula sebaliknya. Dari hasil kompresi dengan algoritma Interpolative Coding diatas dapat dihitung tingkat kinerja kompresinya sesuai parameter yang sudah ditentukan yaitu:

1. Compression Ratio (CR)

$$
\begin{aligned}
& C R=\frac{\text { Ukuran Data Setelah DIkompresi }}{\text { Ukuran Data Sebelum Dikompresi }} \times 100 \% \\
& C R=\frac{136}{256} \times 100 \% \\
& \mathrm{CR}=53 \%
\end{aligned}
$$


Persamaan 2.1 Hasil Compression Ratio (CR) dengan menggunakan algoritma Interpolative Coding sebesar 54 $\%$. Itu berarti setelah dikompresi ukuran data adalah $54 \%$ dari data sebelum dikompresi.

2. Redudancy

$$
\begin{aligned}
& R d=\frac{\text { file sebelum dikompresi }- \text { file setelah dikompresi }}{\text { Ukuran file sebelum dikompresi }} \times 100 \% \\
& R d=\frac{256-136}{256} \times 100 \% \\
& R d=47 \%
\end{aligned}
$$

Persamaan 2.3 Hasil Redudancy dengan menggunakan algoritma Interpolative Coding sebesar $47 \%$. Itu berarti pengulangan data yang terjadi sebesar $47 \%$. dari data sebelum dikompresi.

\section{KESIMPULAN}

Kompresi file audio dapat dilakukan dengan mngubah ke dalam bentuk heksadesimal agar dapat dilakukan perhitungannya. Bilangan heksadesimal yang didapat akan diolah menggunakan algoritma interpolative coding sehingga akan menghasilkan nilai bilangan heksadesimal baru yang akan merubah ukuran dari file audio. Dengan menggunakan Algoritma Interpolative Coding pada file audio maka akan memampatkan ukuran file audio dan menghemat memori penyimpanan.

\section{REFERENCES}

[1] G. M. David Salomon, Handbook Of Data Compression. London Dordrecht Heidelberg New York: Spinger, 2010.

[2] D. Putra, Pengolahan Citra Digital. Yogyakarta: C.V Andi Offset, 2010. 